\title{
Denize dökülen ve batık çalışan akarsu kesitlerinde HEC-RAS ile hesaplanan taşkın su yüzü profilinin Iş1klar Deresi örneği ile incelenmesi
}

\author{
Gökhan AYNA ${ }^{1, *}$, Didem YILMAZER ${ }^{2}$ \\ ${ }^{1} D S \dot{I} 113$. Şube Müdürlüğ̈̈, Tekirdağ \\ ${ }^{2}$ Namık Kemal Üniversitesi, Çorlu Mühendislik Fakültesi, Çorlu, Tekirdă̆ \\ Gelis Tarihi (Received Date): 13.07.2020 \\ Kabul Tarihi (Accepted Date): 03.11.2020
}

\begin{abstract}
$\ddot{\mathbf{O z}}$
Aşırı yağış veya kar erimesi neticesinde oluşan büyük hacimli akımların akarsu yatağına sı̆̆maması olayı taşkın olarak adlandırlmaktadır. Türkiye, bulunduğu coğrafi konumu nedeniyle, özellikle Karadeniz, Marmara, Ege ve Akdeniz bölgelerinde denizlerin etkisiyle yağışların sıkça görüldüğ̈̈ ve buna bağlı olarak can ve mal kayıplarının meydana geldiği bir ülkedir. Yaşanan taşkın olaylarında yerleşim yerlerine yakın kesimlerde ana sebebin çoğunlukla akarsu yataklarına yapılan uygunsuz ve yetersiz müdahaleler ile yanlış imar uygulamalar olduğu görülmektedir. Akarsuların deniz ile buluştuğu kumluk alanlarda ve devamındaki alüvyon düzlüklerde, taşkın sınırı gözetilmeden yapılan imar uygulamaları, birçok mühendislik problemine yol açmaktadır. Bu çalışmada, Tekirdağ ili, Kumbă̆ ilçesi sahil hattında, yerleşim bölgelerinin arasından geçerek denize ulaşan Işıklar deresinde, denize dökülme etkisi ve batık çalışan hidrolik kesitin su yüzü profili HEC-RAS (Hydrologic Engineering Center-River Analisis System) analiz programı yardımıyla modellenmiş ve sonuçlar batık olmayan hidrolik kesitteki su yüzü profili ile karşılaştırılmıştır. Batık çalışan hidrolik kesit ve suyun denize dökülme etkisiyle su yüzü profilinin denize yakın kesimlerde önemli ölçüde düşı̈̈̆ü ve bu düşüş eğiliminin iç kesimlere kadar etkili olduğu görülmüş̧ür.
\end{abstract}

Anahtar kelimeler: Batık çalışan hidrolik kesit, Işıklar Deresi, denize dökülme etkisi, HEC-RAS.

\footnotetext{
*Gökhan AYNA, aynagokhan@gmail.com, https://orcid.org/0000-0001-6047-1291

Didem YILMAZER, didem_yilmazer@yahoo.com, https://orcid.org/0000-0001-6947-8262
} 


\title{
Investigation of flood water surface profile calculated with hec- ras in sunken river sections pouring into the sea by the example of 1şıklar river
}

\begin{abstract}
The phenomenon of large volumes of currents resulting from excessive precipitation or snowmelt not fit in the river bed is called a flooding. Turkey, because of its geographical location, especially because of the impact of the Black Sea, Marmara, Aegean and Mediterranean sea is frequently observed rainfall, and the consequent loss of life and property is a country where occurs. In the flooding incidents experienced, it is seen that the major reason in the areas close to the settlements is mostly inappropriate and inadequate interventions to the river beds and wrong reconstruction practices. Zoning applications on the sandy areas where the rivers meet the sea and on the alluvial flats without considering the flood boundary cause many engineering problems. In this study, the effect of pouring into the sea was investigated in the Işlklar river, which is located in the coastal line of the Kumbağ district of Tekirdağ province and reaches the sea passing through the residential areas, and the water surface profile of the sunken hydraulic section was modeled with the help of the HEC-RAS (Hydrologic Engineering CenterRiver Analisis System) analysis program and the results were compared with the profile of the water face in the non-submerged hydraulic section. With the effect of submerged hydraulic section and water pouring into the sea, it was observed that the water surface profile decreased significantly in the sections close to the sea and it was also observed that this downward trend was effective until the inner parts.
\end{abstract}

Keywords: Submerged hydraulic section, Işıklar River, Spilling effect to the sea, HECRAS.

\section{Giriş}

Taşkın kontrol çalışmaları, planlama aşamasında havza bazında gözlem, inceleme ve veri toplamayı gerektiren, projelendirme, inşaat ve işletme aşamalarında birçok disiplinin birlikte yürüttüğü çalışmaların bütününe verilen isimdir. Bilgisayar teknolojilerinin gelişmesi ile hidrolojik verilerin uzaktan toplanarak işlenmesi, topografik verilerin uydu veya diğer fotogrometrik yöntemler ile kolayca ve hızlı bir şekilde toplanabilmesi, 3 boyutlu akışkan hareketlerinin sayısal modelleme yoluyla yüksek doğruluk oranlarında çözümlenebilmesi, taşkın kontrol çalışmalarının planlama ve projelendirme aşamalarına önemli bir ivme kazandırmıştır.

Bunun yanında, hesaplamalı akışkanlar dinamiğinde bilgisayar sayesinde sağlanan ilerleme sayısal modelleme çalışmalarının çeşitlenmesine, akışkan-yapı etkileşiminden [1] geliştirilen özel yazılımlar ile havza bazlı akış modellenmesine [2] kadar birçok çalışmanın yapılmasına olanak tanımıştır. Ücretsiz olarak servis edilmiş olması, pratik yapısından ve hızlı çözüm alabilme kapasitesinden dolayı uygulama alanlarında oldukça yoğun kullanıma sahip olan HEC-RAS yazılımı da bu özel yazılımlardan biridir. Uygulama çalışmalarındaki yoğun kullanımının yanında literatürde, akademik alanda da HEC-RAS yazılımı kullanılarak yapılan; akarsu üzerinde bulunan çoklu köprü 
sistemlerinin akış alanı üzerindeki etkilerinin 1 boyutlu ve 2 boyutlu olarak çözümlendiği ve sonuçların karşılaştırıldığı çalışmalar [3], Taşkın sırasında akarsuyun denize döküldüğü kıyı hattında oluşan oyulmaların ve zararların modellendiği çalışmalar [4], akarsuyun manning pürüzlülük katsayısının kalibrasyonunun yapılması için taşkın sırasında kaydedilen istasyon ölçümleri ile HEC-RAS programından alınan model sonuçlarının karşılaştırıldığı çalışmalar [5,6], baraj yıkılması durumunda mansapta oluşacak taşkın yayılım alanlarının haritasının 2 boyutlu modellemesi hakkında çalışmalar [7], deniz su seviyesinin taşkın alanlarına etkilerinin sayısal modeller kullanılarak incelendiği çalışmalar [8] ve taşkın risk haritasını hazırlamak veya daha detaylı hale getirmek için sayısal modellerin kullanıldığı [9] çalışmalar, akarsuda taşkın modellemesinin yapıldı̆̆ çalışmalar[10] gibi akışkan hareketi üzerine çeşitli çalışmalar mevcuttur.

Bu çalışmanın konusu, Tekirdağ ili, Kumbağ ilçesi sahil hattında, yerleşim bölgelerinin arasından geçerek denize dökülen Işıklar deresinde, denize dökülme etkisi ile batık çalışan hidrolik kesitin su yüzü profilinin elde edilmesi ve sonuçları batık olmayan hidrolik kesitteki su yüzü profili ile karşılaştırılmasıdır.

\section{Yöntem}

$\mathrm{Bu}$ çalışmada taşkın riski taşıdığı tespit edilen, Naip Barajı mansabında bulunan Işıklar Deresinin denizle buluştuğu sahil hattından itibaren 650 metrelik kısmında, dere yatağının doğal eğimine uyularak bir hidrolik kesiti tasarlanmış ve manning hız denklemi ile süreklilik denklemi kullanılarak taşkın su yüzü kotlarının belirlenmesi hususunda bir ön çalışma yapılmıştır. Sonrasında aynı kesit denize doğru daha yüksek bir eğimle batık hidrolik kesit olarak tasarlanmış ve Autocad Civil 3D programı ile 3 boyutlu olarak modellenmiştir. $\mathrm{Bu}$ modelden 1 metre aralıklarla alınan kesitler, mansap ve menba koşullarını dikkate alarak çözüm yaptığı bilinen HEC-RAS programında modellenmiştir. Deniz dalga yüksekliği modele mansap şartında sabit su kotu olarak girilmiş ve model çalıştırılmıştır. Elde edilen su yüzü kotları yapılan ön çalışma ile karşılaştırılmıştır.

Çalışmada kullanılan HEC-RAS programı, "US Army Corps of Engineers Institute of Water Resources Hydraulic Engineering Center" tarafından, doğal nehir yatakları ve inşa edilen taşkın kanalları ağlarının tamamını, taşkın yatağı alanlarının, arazi koruma alanlarının vb. bir ve iki boyutlu hidrolik analizlerinin gerçekleştirilmesi için geliştirilmiştir. Program aynı zamanda, hareketli yataklarda sediment hareketlerinin hesaplanmasına; su sıcaklığı ve su kalitesi modellemelerine; baraj yıkılması analizi veya taşkın seddelerinin yıkılması analizi gibi karmaşık modellerin oluşturulmasına izin verir [11].

HEC-RAS'ta bir boyutlu sürekli değişen akış için, sel rejiminde ve/veya nehir rejiminde su yüzü profilinin modellenmesini gerçekleştirebilmektedir. Programda, basit profil hesaplamalarında su yüzü profili, bir kesitten diğerine, "standart adım metodu" olarak isimlendirilen bir iterasyon prosedürüyle çözülen enerji denklemi ile hesaplanmaktadır. Enerji denklemi aşağıda verilmiştir [12]:

$Z_{2}+Y_{2}+\frac{a_{2} V_{2}^{2}}{2 g}=Z_{1}+Y_{1}+\frac{a_{1} V_{1}^{2}}{2 g}+h_{e}$ 
Burada;

$\mathrm{Z}_{1}, \mathrm{Z}_{2}=$ Kesit talveg kotu

$\mathrm{Y}_{1}, \mathrm{Y}_{2}=$ Kesitteki su derinliği

$\mathrm{V}_{1}, \mathrm{~V}_{2}=$ Ortalama debi (toplam deşarj / toplam akış alanı)

$\mathrm{a}_{1}, \mathrm{a}_{2}=$ Hız ağırlı̆g 1 katsayısı

$\mathrm{g}=$ Yerçekimi ivmesi

$h_{\mathrm{e}}=$ Enerji kaybi [12].

Bir kesit için hız dağılımının ve toplam debinin belirlenmesi için akışın hız dağılımının uniform olduğu alt bölümlere bölünmesi gerekir. HEC-RAS ta kullanılan bu yaklaşımda akış, n pürüzlülük değerinin değiştiği noktalar kullanılarak bölümlere ayrılır. Her alt bölümdeki akış debisi, aşağıda verilen Manning hız denkleminin bir formu olan denklem ile hesaplanır ve kesit için toplam debi sol sahil, sağ sahil ve kanal bölümündeki (Şekil 1) debilerin toplanmasıyla elde edilir [12].

$Q=K S_{f}^{1 / 2}$

$K=\frac{1,486}{n} A R^{2 / 3}$

Burada;

$\mathrm{K}=$ Alt bölüm taşıma hızı

$\mathrm{n}=$ Alt bölüm manning pürüzlülük katsayısı

A = Alt bölüm akış alanı

$\mathrm{R}=$ Alt bölüm hidrolik yarıçapı

$\mathrm{S}_{f}=$ Enerji çizgisinin eğimi [12].

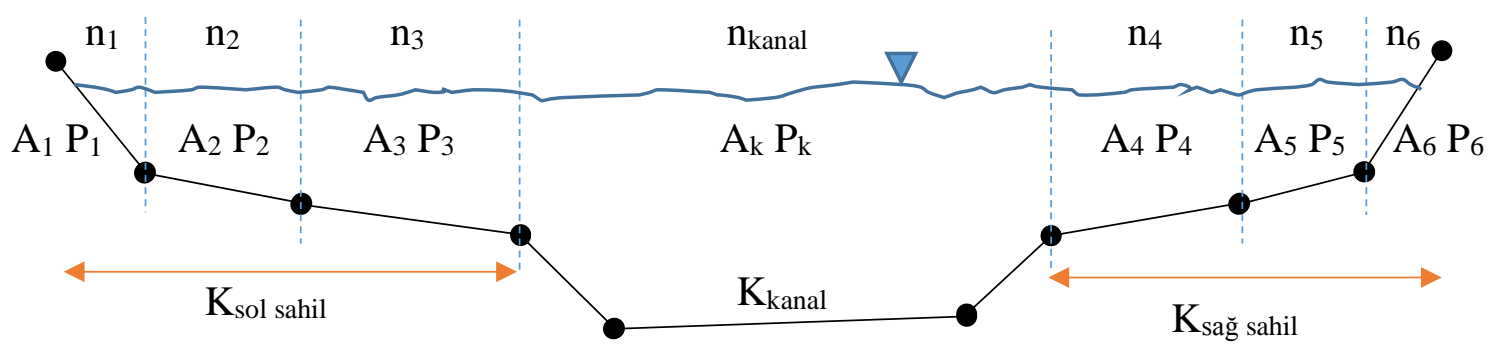

Şekil 1. HEC-RAS ta kesiti alt bölümlere ayırma yöntemi.

\section{Uygulama alanı}

Tekirdağ ili Balkanlardan gelen hava akımlarına maruz kalan ve özellikle Kasım- Mart ayları arasında yağışların hâkim olduğu bir iklim bölgesinde yer almaktadır. Bunun yansıra İstanbul'a yakınlığı nedeniyle sahil hattı boyunca yazlık turizminin bolca görüldügü ve neredeyse tüm sahil hattının yapılaşmaya açık olduğu bir sahil kentidir. Özellikle denize dökülen akarsuların oluşturduğu kumluk alüvyon ovalarında yapılaşma iç kesimlere kadar ilerlemiştir. Alüvyon ovalarında arazi eğiminin neredeyse sıfır ve rakımın oldukça düşük olması neticesinde yaşanan tüm yă̆ışlarda sürekli doygun durumdaki zemin sebebiyle üst havzadan gelen sular ovada kabararak yerleşim yerlerinde su baskınlarına sebep olmaktadır. 
Tekirdağ İline bağlı Kumbağ ilçesi içinden geçerek denize dökülen Işıklar Deresi'de yukarıda bahsedilen bu özelliklere sahip derelerden biridir. Üst havzadan gelen sel sularının Işıklar Deresi'nin denizle buluştuğu alüvyon ovasına yayılmadan denize ulaşabilmesi için hidrolik kesitin batık çalıştırılması gerekmektedir. Aksi durumda tasarlanacak bir 1slah kesitinde, sahile yaklaştıkça yüksek sedde veya duvar kotlarıyla karşılaşılacaktır. Bu seddeler ile arkasındaki son derece düz olan alüvyon ovasında yer alan yerleşim alanlarının oluşturduğu geçirimsizlik, yüzeyde toplanan suların dereye tahliyesine engel olacak ve geneli kıyı hattına paralel olan yol dolguları ile sedde veya duvarlar arasında hapsolan su birikintileri oluşması durumuyla karşı karşıya kalınacaktır.

Naip Barajını dolduran Işıklar deresi (Resim1) barajın mansabında Tekirdağ ili Kumbağ ilçesinden geçerek denizle buluşmaktadır. Tatil turizminin yoğun olduğu kentte imar uygulamasında 2 katlı yazlık modeli hâkimdir. Doğal durumda derenin denize yakın 600 metrelik kesiminde taban eğimi $(0,0015)$ oldukça düşüktür. Işıklar Deresinin 100 ve 500 yıllık taşkın tekerrür debileri sırasıyla, $185 \mathrm{~m}^{3} / \mathrm{sn}$ ve $282 \mathrm{~m}^{3} / \mathrm{sn}$ dir [13]. Derenin denize döküldüğü hat üstünde akış doğrultusunda sağ ve sol sahilde yer alan yerleşim alanlarında su basman kotu $0.70 \mathrm{~m}$ ile $1.20 \mathrm{~m}$ arasında değişmektedir.

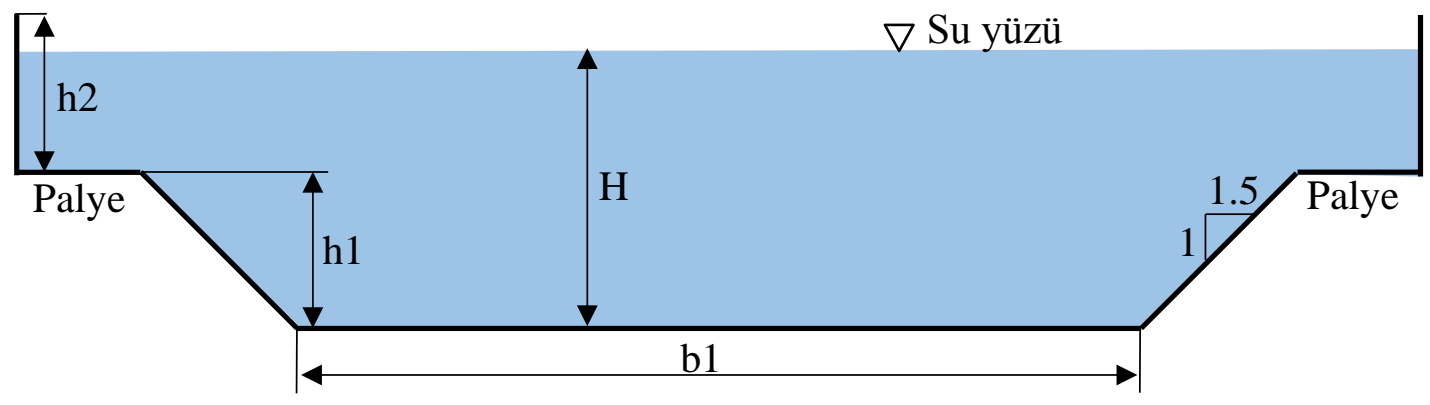

Şekil 2. Işıklar deresi hidrolik kesiti.

100 yıllık ve 500 yıllık taşkın tekerrür debilerinin büyüklüğü düşünüldüğünde, doğal en kesit talveg eğimi $(0,0015)$ ve klasik manning denklemi ile Şekil 2 de verilen kademeli hidrolik kesit için hesaplanan su kotuna göre (Tablo 1) bir 1slah çalışması yapıldığı durumda hesaplanan duvar kotlarının yerleşim yerinde estetik olarak uygun olmayacak ve duvarın dış kesiminde drenaj sorunları da yaratacaktır.

Tablo 1. Işıklar deresi hidrolik kesitine ait kapasite hesabı.

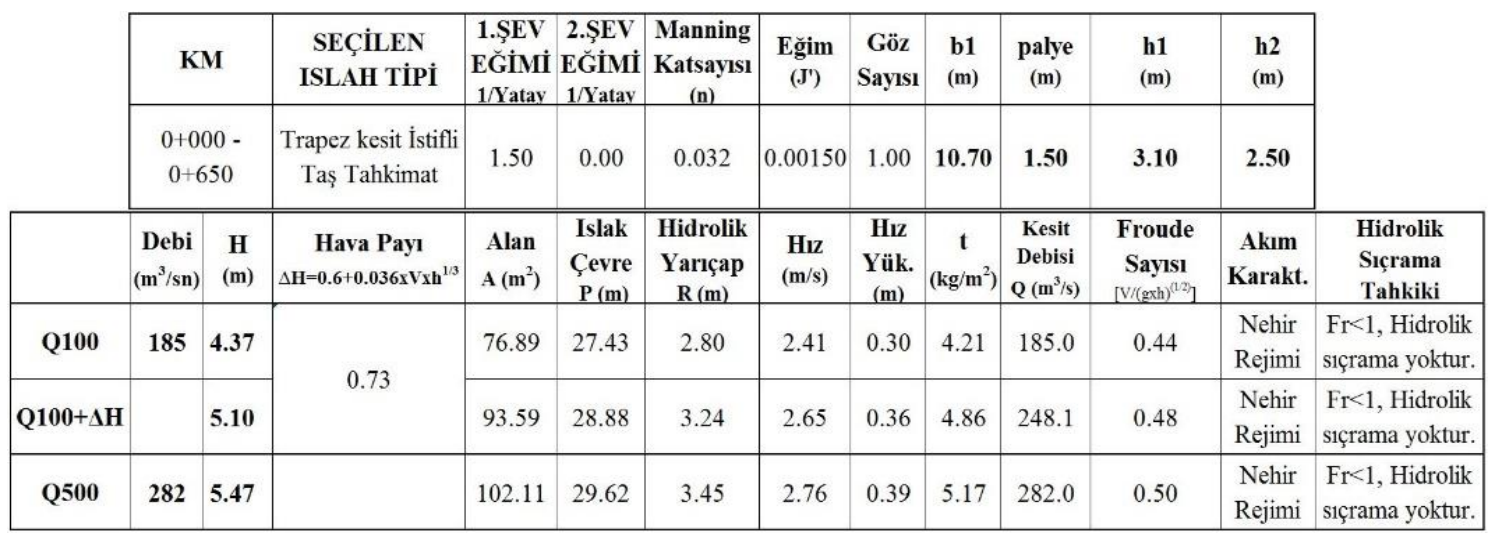


Bu sebeple, kıyıdan itibaren 650 metreye kadar ki kesimde taban eğimi arttırılarak $(0,0051)$ batık hidrolik kesit çalışılması düşünülmüştür. Bununla birlikte batık hidrolik kesit kanalda sürekli deniz suyu bulunmasına yol açacaktır. Islah kanalının denizden gelen dalgalara doğrudan maruz kalması, sel sırasında kanal akışını etkileyecek, sakin dönemde de deniz dalgaları ile kanal tabanının kumla dolması neticesinde batık hidrolik kesitin kapasitesi düşecektir. Bu sebeple ıslah kanalının denizle buluştuğu noktadan itibaren denizin iç kesimlerine ilerleyen paralel mahmuz yapısı (Resim 1.) planlanarak, deniz dalga etkisinin kanal akışını etkilemesi ve kesit içine kum taşınmasını engellenmiştir.

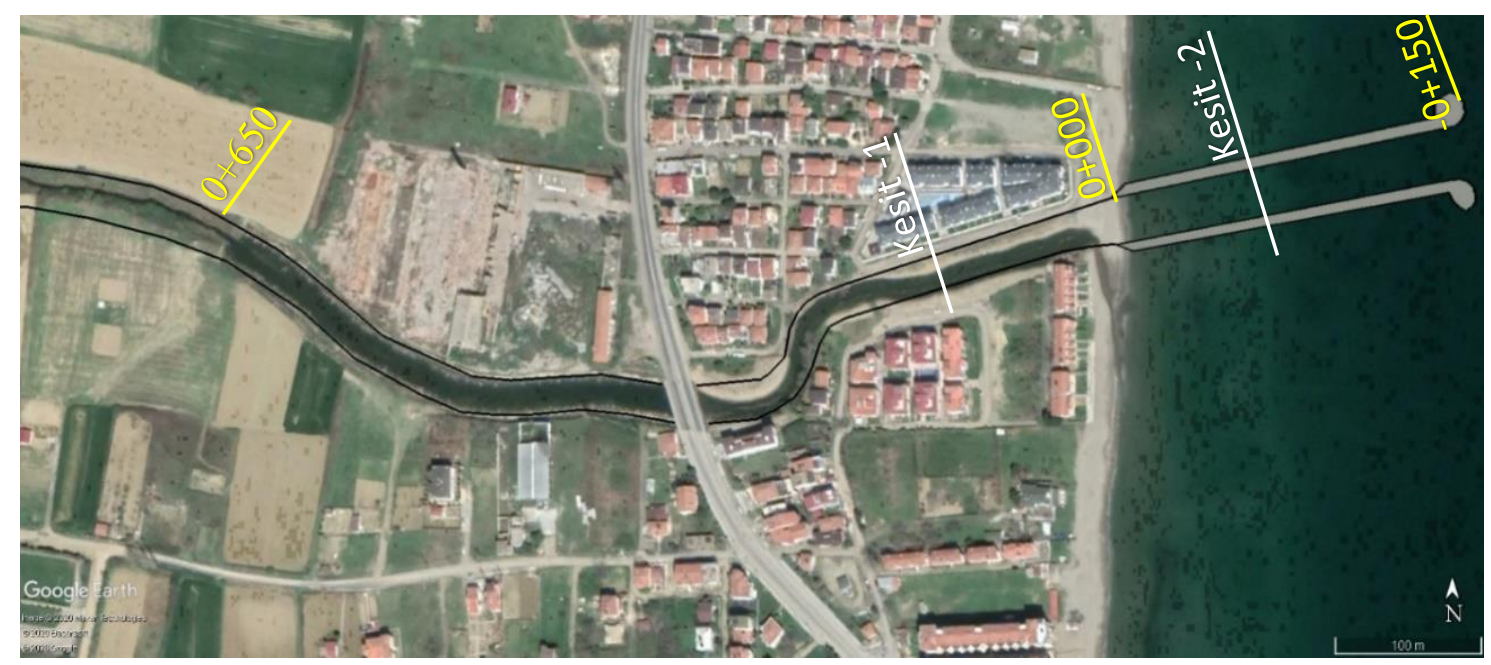

Resim 1. Işıklar Deresi genel görünüm.

\section{Sayısal model}

Bu çalışmaya konu olan Işıklar deresi'nde, kısmi batık çalışan iki kademeli hidrolik kesit (Şekil 3), denize doğru uzanan mahmuz yapısı ve deniz tabanının oluşturduğu hidrolik kesit (Şekil 4) batimetrik haritaların da yardımıyla Autocad Civil 3D ortamında modellendikten sonra HEC-RAS programına aktarılmıştır. Tasarlanan kesit istifli taş tahkimat ve kâgir kıyı duvarı olarak düşünüldüğünden manning katsayısı DSİ Modifiye Cowan Yöntemiyle [14] aşağıdaki şekilde hesaplanmış ve 0,032 olarak belirlenmiştir.

$n=\left(n_{b}+n_{1}+n_{2}+n_{3}+n_{4}\right) m$

Burada;

$\mathrm{n}_{\mathrm{b}}=$ Kanalın zemin özelliklerine göre seçilen katsayı olup, 0,025 seçilmiştir.

$\mathrm{n}_{1}=$ Yüzey düzensizliklerinin etkileri için düzeltme katsayısı olup, kesitin trapez kısmının şevleri istifli taş tahkimat palye üstündeki düz kısım ise kâgir kıyı duvarıdır. Bu sebeple bu düzeltme katsayısı 0,007 olarak seçilmiştir.

$\mathrm{n}_{2}=$ Kanal kesit değişimi katsayısıdır. Bu değer 0 olarak alınmıştır.

$\mathrm{n}_{3}=$ Kanalda ki engellerin etkisi için belirlenmiş bir katsayıdır. Bu değer 0 alınmıştır.

$\mathrm{n}_{4}=\mathrm{Akım}$ şartları ve bitki örtüsü için seçilen bir katsayıdır. Bu değer batık kesitteki tuzlu sudan dolay 0 olarak seçilmiştir.

$\mathrm{m}=$ Kanalın kıvrım derecesini ifade eden bir katsayıdır. Bu değer 1 olarak seçilmiştir. 


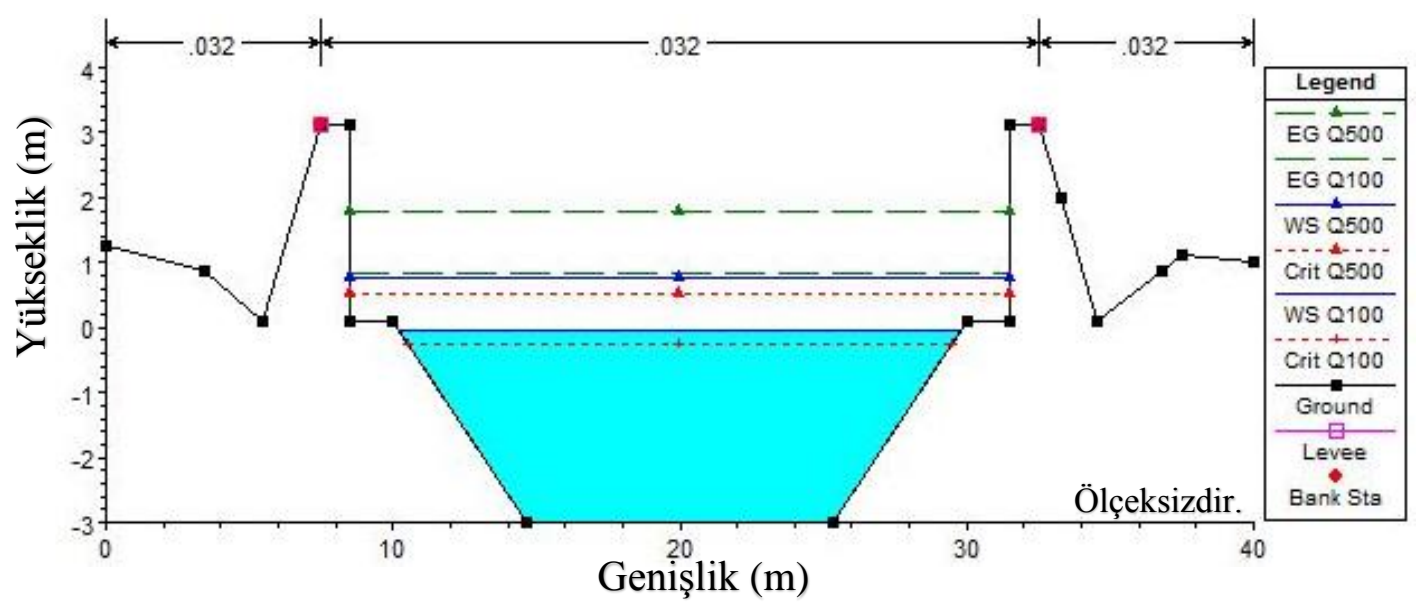

Şekil 3. Batık çalışan Hidrolik Tip Kesit-1 (km :0+000 ile 0+650 arasında).

Tasarlanan kadelemeli hidrolik kesitte (Şekil 3), trapez kesitli ilk kademe özellikle denize yakın kısımda büyük oranda batık olarak çalışacaktır.

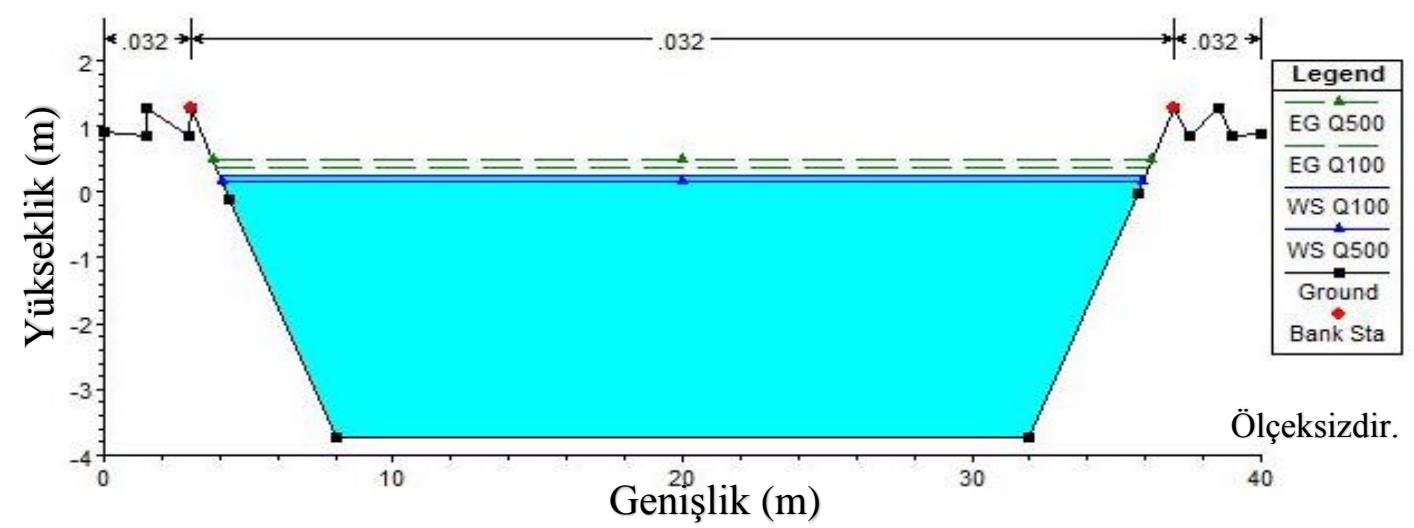

Şekil 4. Mahmuz Yapısı Hidrolik Tip Kesit-2 (km : - 0+150 ile 0+000 arasında).

Denizden gelebilecek partikül hareketlerini sınırlamak ve deniz dalga etkisinin iç kısımlara ilerlemesine engel olmak için sahil hattından itibaren denize doğru 150 metre uzunluğunda, şev üstünden şev üstüne 35 metre açıklıklı şev eğimleri 1/1 olan birbirine paralel bir çift mahmuz yapısı planlanmış ve deniz içindeki mahmuz kesitinde (Şekil 4) Manning katsayısı 0,032 olarak alınmıştır.

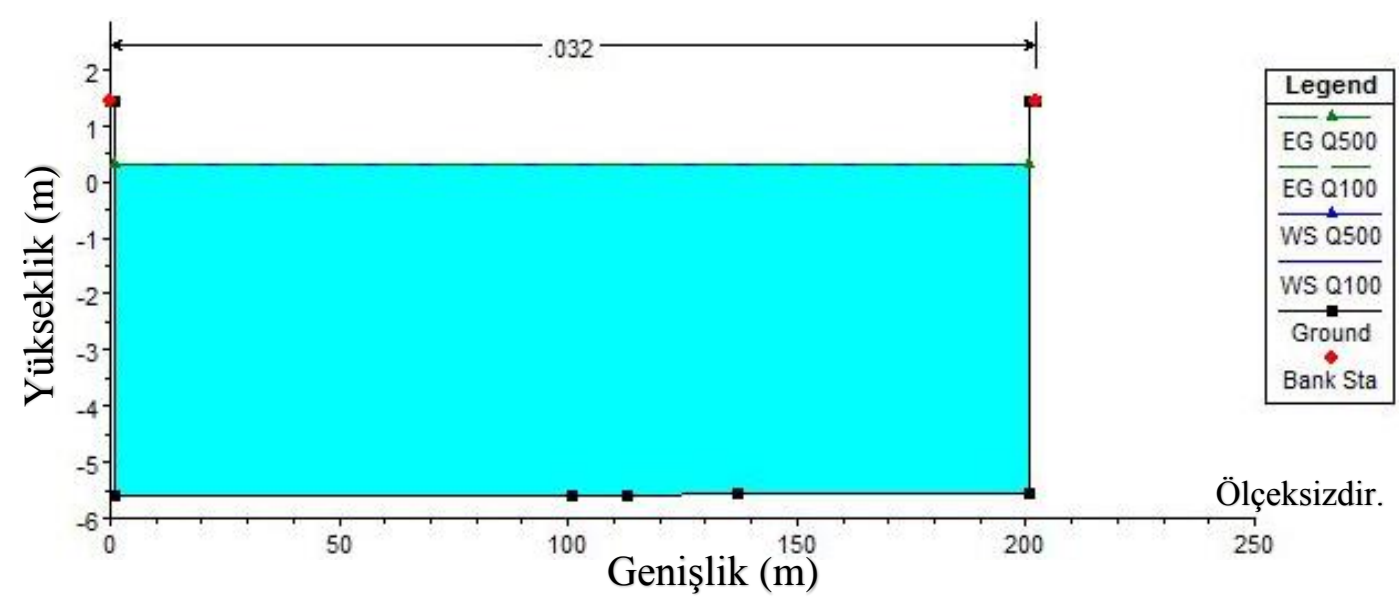

Şekil 5. Deniz batimetresi modeli (km : $-0+220$ ile $-0+150$ arasında). 
Ayrıca, denize doğru mahmuz yapısından sonra 70 metre daha ilerleyerek deniz içinde batimetrik haritalardan alınan deniz tabanı modelinin 200 metrelik bir kesiti (Şekil 5) (-) yönde modele dâhil edilmiştir. Bu kesitte mansap şartı olarak sabit su seviyesi tanımlandığından dolayı her iki profil içinde (Q100 ve Q500) Su yüzü kotları aynı olurken; kesit çok geniş seçildiğinden dolayı da her iki profil içinde (Q100 ve Q500) düşük akış hızı (sırasıyla, $0,14 \mathrm{~m} / \mathrm{s}$ ve $0,22 \mathrm{~m} / \mathrm{s}$ ) oluşmakta ve enerji çizgisi kotları ile su yüzü kotları neredeyse aynı seviyede toplanmaktadır (Şekil 5).

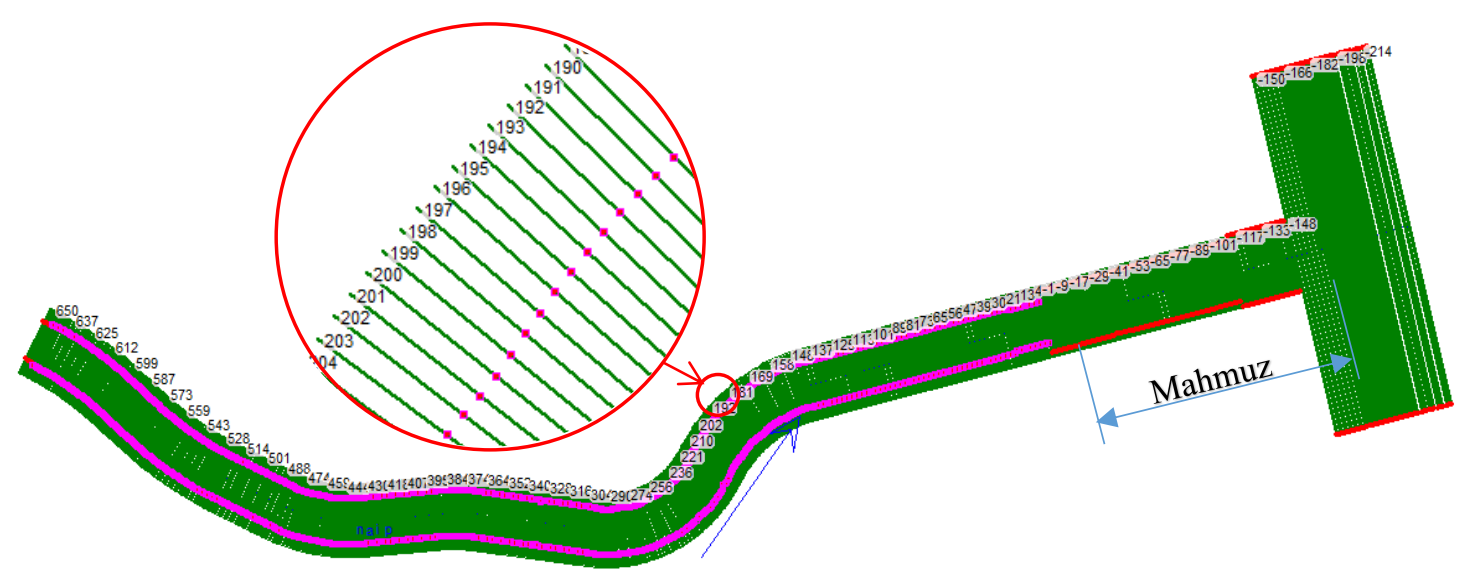

Şekil 6. Işıklar Deresi planı.

HEC-RAS modeli, Naip Barajı Mansap şartı kapsamında 1slahı yapılacak olan Işıklar deresinin yerleşim alanlarına yakın olan 650 metrelik kısmında su yüzü profilini detaylı görebilmek için 1.0 metre aralıklı kesitler tanımlanarak (Şekil 6) akış planı oluşturulmuştur.

HEC-RAS programında memba ve mansap koşulları; bilinen su seviyesi, kritik derinlik, normal derinlik ve anahtar eğrisi şeklinde dört seçenekte girilebilmektedir. Bu çalışmada, başlangıç koşulu olarak normal derinlik seçilmiş ve açılan pencereden membadaki kanalın eğimi $(0,00437)$ tanımlanmıştır.

Mansap kısmında ise, denizin dalga etkisini azaltmak için her ne kadar mahmuz yapısı planlansa da [15] tarafından oluşturulan dalga atlasından (Şekil 7) faydalanılarak, ışıklar deresinin deniz ile buluştuğu noktada 31 yıl boyunca tahmin edilmiş maksimum dalga yüksekliğinin 2 metre olduğu tespit edilmiştir. Oluşturulan 150 metrelik Mahmuz modelinde dere ağzında maksimum dalga yüksekliği yapılan ön hesaplamalar ile yaklaşık 0,50 metre olarak bulunmuş ve model mansap koşuluna bilinen su seviyesi 0,50 m olarak girilerek bu dalga etkisi de benzeştirilmiştir. 

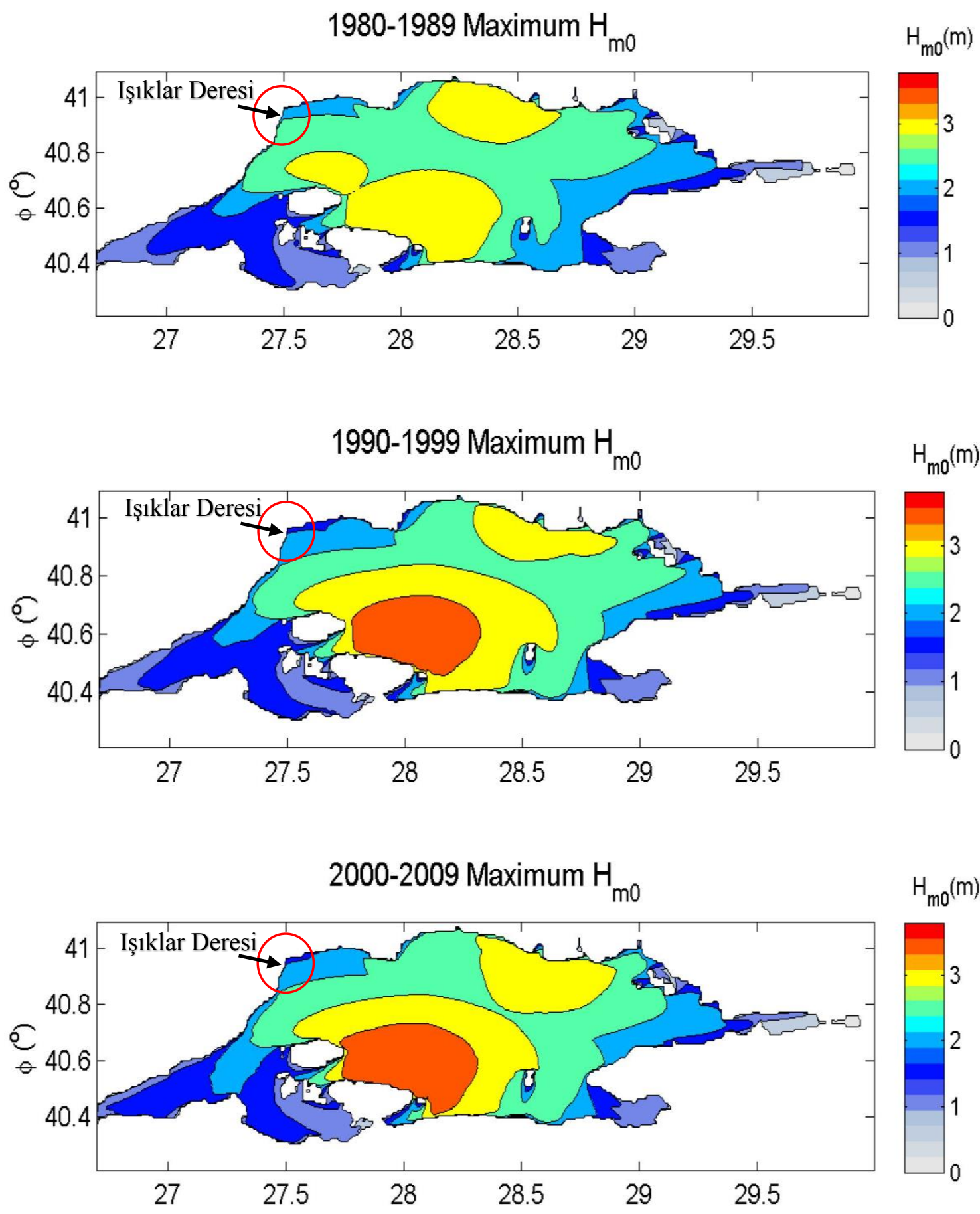

Şekil 7. CFSR rüzgarlarını kullanan kalibre edilmiş SWAN model sonuçlarından elde edilen 31 yıl boyunca tahmin edilmiş belirgin dalga yüksekliklerinin 10'ar yıllık maksimum değerlerinin alansal dağılımları [15]. 


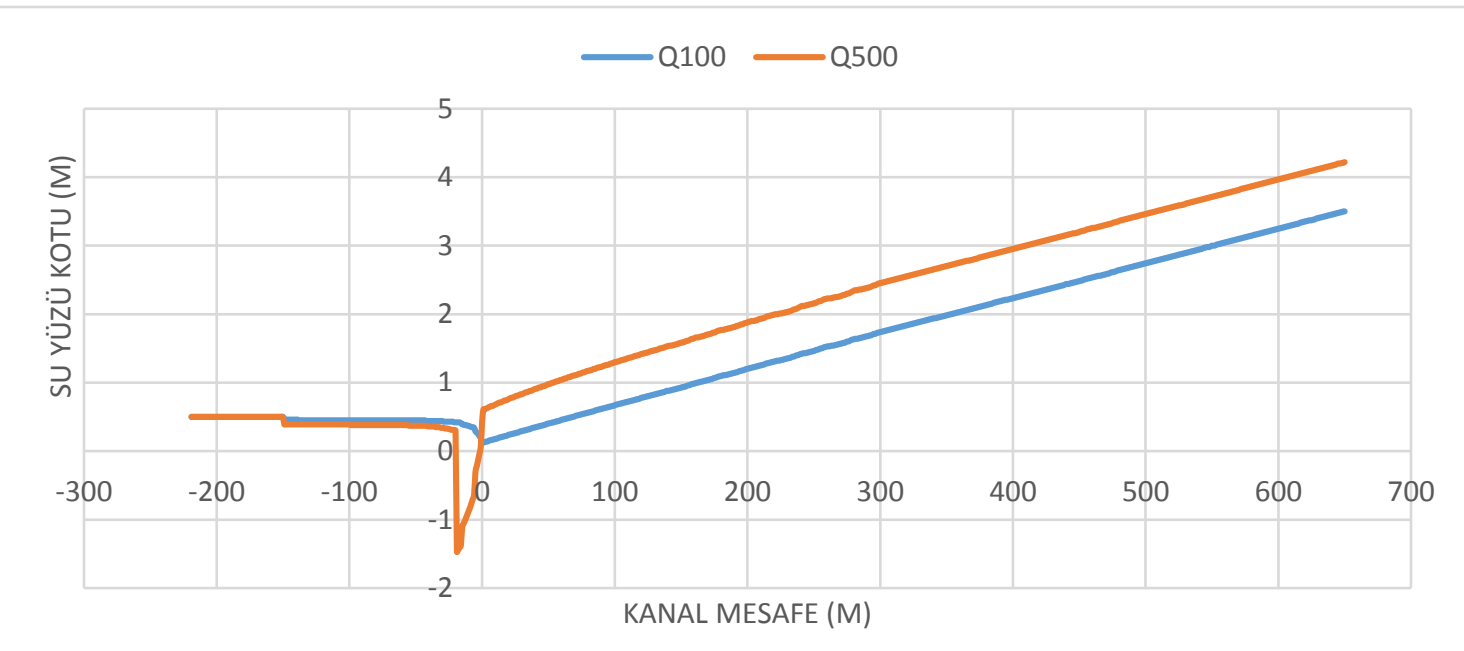

Şekil 8. -0+220 / 0+650 HEC-RAS ta hesaplanan Q100 ve Q500 su yüzü kotları.

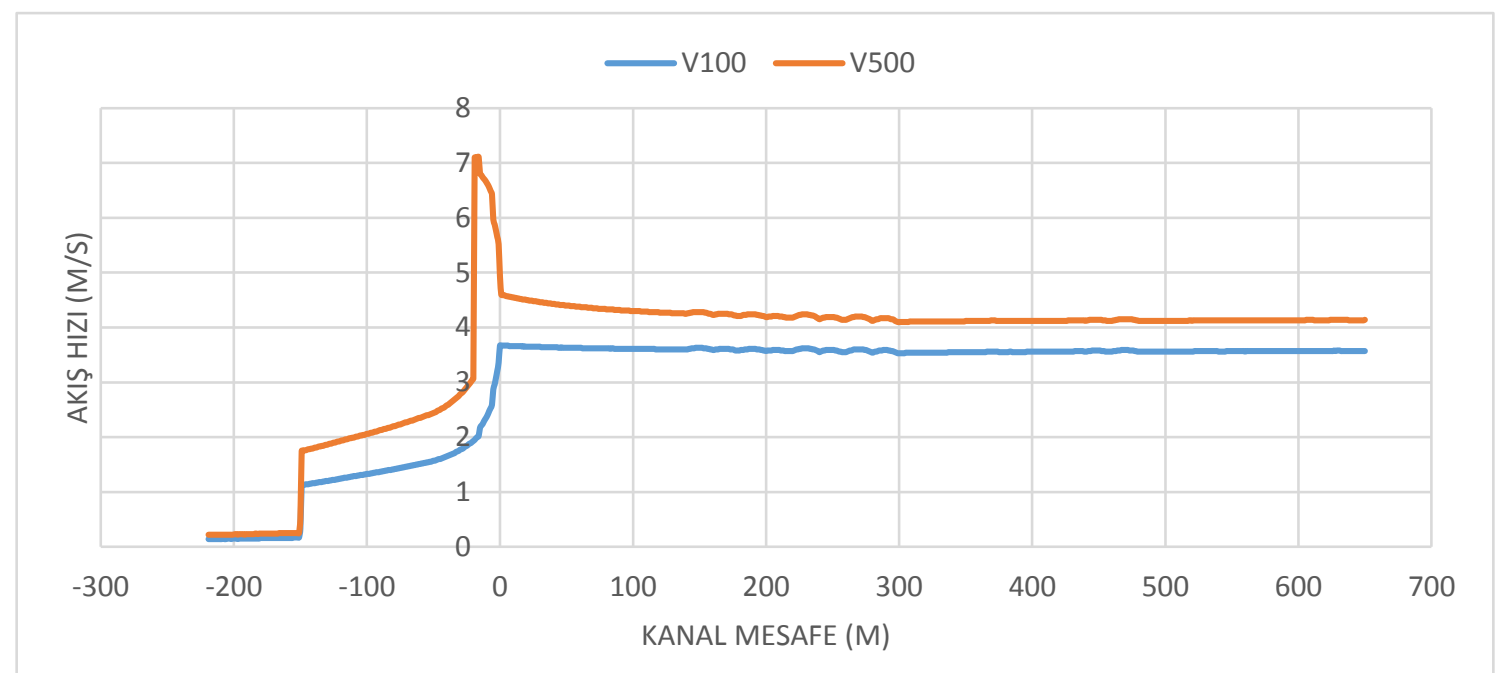

Şekil 9. -0+220 / 0+650 HEC-RAS ta hesaplanan Q100 ve Q500 su yüzü kotlar1.

HEC-RAS'ta Q100 ve Q500 taşkın tekerrür debileri ile elde edilen hız ve su yüzü profilleri (Şekil 8-9) incelendiğinde, kesit değişiminin bulunduğu km: 0+000'da su yüzü ve hız profillerinde ters yönde farklılık olduğu görülmüştür. Mansap şartı olarak tanımlanan $0,5 \mathrm{~m}$ sabit su seviyesi ve süreklilik denklemi ile enerjinin korunumu yasası gereği Q100 debisinde, beklendiği gibi ani kesit genişlemesiyle hız düşerken su yüzü kotu yükselmekte ve mansap sınır koşulu olan 0,5 metre su kotuna yakınsamaktadır.

Ancak, Q500 debisinde ani kesit geniş̧lemesine rağmen hız, akış su yüzü kotu mansap şartı su kotunun üzerinde kaldığı için dökülme etkisiyle önce artmış sonrasında oluşan çalkantıyla enerjisini bir miktar kaybetmiş ve ani bir şekilde düşmüştür. Bu ani düşüşten sonra Q100 debisinde olduğu gibi hız yavaşça düşerken su yüzü kotu da mansap sınır koşulu olan 0,5 metre kotuna yakınsamaktadır. 


\section{Sonuçlar}

Bu çalışmada, Tekirdağ ili, Kumbağ ilçesi sahil hattında, yerleşim bölgelerinin arasından geçerek denize dökülen Işıklar deresinde, denize dökülme etkisinin ve batık çalışan hidrolik kesitin su yüzü profilinin HEC-RAS analiz programı yardımıyla modellenmesi ve sonuçların günüzmüzde hala oldukça sık kullanılan manning denklemi ile hesaplanan batık olmayan hidrolik kesitteki su yüzü profili ile karşılaştırılması amaçlanmıştır. Bu amaçla, kısmi batık çalışan kademeli hidrolik kesit ve denize doğru uzanan mahmuz yapısı ile deniz tabanının oluşturduğu hidrolik kesit, batimetrik haritaların da yardımıyla Autocad Civil 3D ortamında üç boyutlu olarak modellenmiştir.

Batık hidrolik kesitli bir akarsuda ani baskın şeklinde yaşanan taşkınlarda sabit su seviyesinin 2. bir taban gibi davranıp akışı kabartması muhtemeldir. Buna karşın, Işıklar deresi menbaında ana kol üzerinde Naip barajının olması, 1şıklar deresi yan kollarında oluşan pik yağışların ana kol pik debisi ile çakışmasını ötelemektedir. Ayrıca, Tekirdağ ilinin toprak yapısının geçirgen olması, bitki örtüsü yoğunluğu ve yağış rejimleri göz önüne alındığında yağış sırasında su seviyesinin ani olmak yerine belli bir zaman aralığında yükseleceği ve bu durumun batık hidrolik kesitin kapasitesinin taşkın yaratmadan akışa katılmasına izin vereceği düşünülmektedir.

Batık olmayan kesitteki su hızı taban eğimi düşük olması nedeniyle ortalama $2.30 \mathrm{~m} / \mathrm{s}$ çıkarken batık kesitteki su hızı ortalama $3.65 \mathrm{~m} / \mathrm{s}$ olarak bulunmuştur. Her ne kadar batık hidrolik kesitte neredeyse durağan bir su kütlesi bulunuyor olsa da taban eğiminin artıyor olması ve buna bağlı olarak su hızının artmasıyla batık hidrolik kesitin su yüzü kotunun düşürülmesinde oldukça önemli etkilerinin olduğu görülmüştür (Şekil 10 -11). Bu sebeple özellikle akarsuların deniz ile buluştuğu kıyı hattında manning denklemi ile tek kesit üzerinden hesap yapmak yerine HEC-RAS gibi iki boyutlu analiz yapabilen programlar ile akışın deniz kısmı da modele dahil edilerek ve mansap su kotu dikkate alınarak hesap yapılması $\mathrm{Su}$ yüzü profillerinin ve buna bağlı olan taşkın koruma kıyı duvarı kotlarının daha makul ve gerçekçi projelendirilmesini mümkün kılacaktır.

Ayrıca, batık çalışan hidrolik kesitli akarsularda, akışın deniz dalgalarından etkilenmesini önlemek ve batık çalışan hidrolik kesitin denizden gelebilecek partiküller ile dolmasına engel olmak için akarsuyun deniz ile buluştuğu noktadan başlamak üzere denize doğru birbirine parallel bir çift mahmuz veya liman gibi dalgaların iç kesimlere ilerlemesini önleyici yapılar yapılması zorunludur. Aksi takdirde batık kesit, denizden sürüklenen partiküller ile dolacak ve zamanla oluşan bu birikintiler sel sırasında akışın kabarmasına sebep olacaktır.

İlerleyen çalışmalarda batık hidrolik kesitli akarsuların ani debi artışlarında ve farklı deniz dalga seviyelerindeki davranışlarını, dalga dinamiği ve akarsu hidrodinamiğini aynı projede işleyebilen ve sonlu hacimler metodu ile daha kapsamlı analizler yapabilen Flow 3D gibi programlar yardımıyla irdelenmesi düşünülmektedir. 


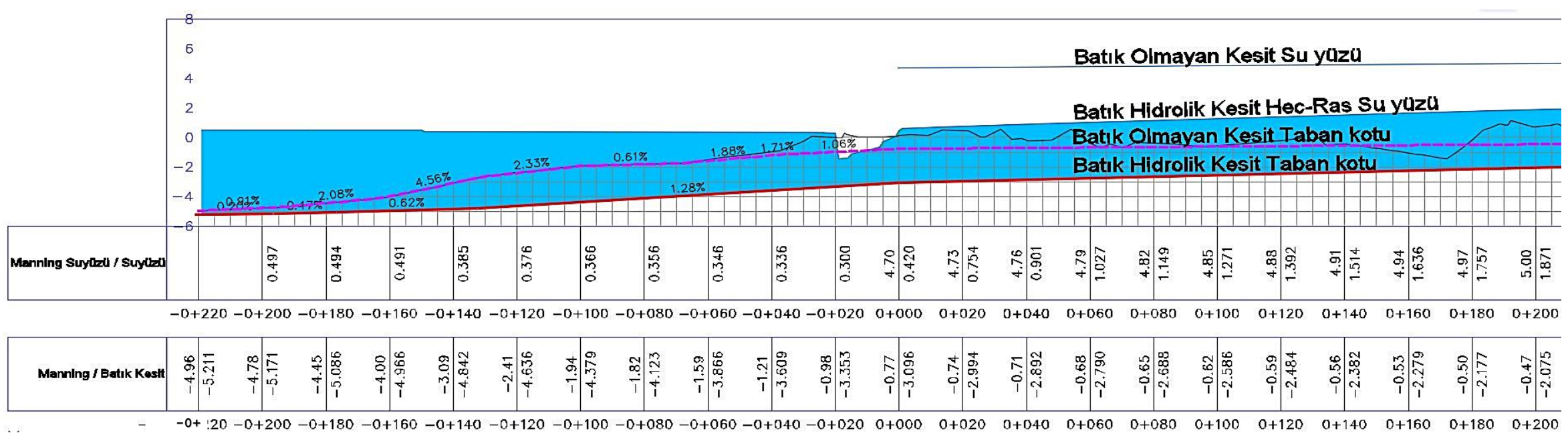

Şekil 10. -0+220 / 0+210 Q500 su yüzü profilleri.

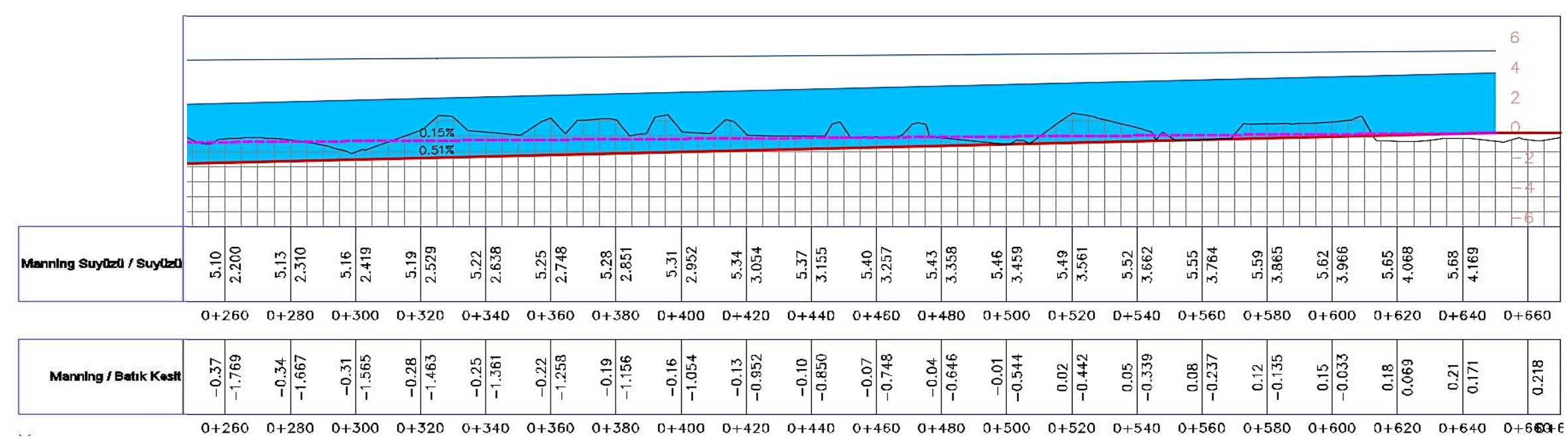

Şekil 11. 0+210 / 0+650 Q500 su yüzü profilleri. 


\section{Kaynaklar}

[1] Kirkgoz, M.S., Aköz, M.S.,Öner, A.A, Experimental and theoretical analysis of two-dimensional flows upstream of broad-crested weirs, Canadian Journal of Civil Engineering, 35, 9, 975-986, (2008).

[2] Elizabeth, S. Garcia and Hugo A. Loáiciga, Sea-level rise and flooding in coastal riverine flood plains, Hydrological Sciences Journal, Journal des Sciences Hydrologiques, 59,1, (2014).

[3] Evan, C., Deal, A., Comparison studg of one - and two dimensional hydraulic models for river environments, Yüksek Lisans Tezi, University of Kansas, Kansas, (2015).

[4] Szydłowski, M., Hydraulıc analysıs of causes of washout of gdynia-orłowo seashore durıng the flood In the kacza river estuary, Polish Maritime Research, 101,26,174-182, (2019).

[5] Parhi, P., Sankhua, R. and Roy, G., Calibration of channel roughness for Mahanadi River, (India) using HEC-RAS model, Journal of Water Resource and Protection, 4, 10, 847-850, (2012).

[6] Timbadiya, P., Patel, P. and Porey, P., Calibration of HEC-RAS Model on prediction of flood for lower Tapi River, India, Journal of Water Resource and Protection, 3, 11, 805-811, (2011).

[7] Dursun, Ö. F., Gül, E., İki boyutlu baraj yıkılma modellemesi; sürgü barajı örneği, Fırat Üniversitesi Mühendislik Bilimleri Dergisi, 30, 3, 97-104, (2018).

[8] Burgan, H.İ., Kırca, V.Ş.Ö., Aksoy, H., Deniz su seviyesinin taşkın alanlarına etkisi, 4. Ulusal Taşkın Sempozyumu, 749-755, Rize, (2016).

[9] Stoleriu, C.C., Urzica, A., Mihu-Pintilie, A., Improving flood risk map accuracy using high-density LiDAR data and the HEC-RAS river analysis system: A case study from north-eastern Romania, Journaş of Flood Risk Management, 13, S1, (2019).

[10] Hidayat, B., Istijono, B., Irwan, Ophiyandri, T. and Junaidi, A., The effects of Batang Kandis River flood control in Padang city-Palapa metropolitan urban area, International Journal of GEOMATE, 19, 71, 9-14, (2020).

[11] HEC-RAS River Analysis System, User's Manual for version 5.0, CPD-68 (downloadable from https://www.hec.usace.army.mil/software/hecras/documentation/HEC-RAS\%205.0\%20Users\%20Manual.pdf ) (2016).

[12] HEC-RAS River Analysis System, Hydraulic Reference Manual 5.0, CPD-68 (downloadable from https://www.hec.usace.army.mil/software/hecras/documentation/HEC-RAS\%205.0\%20Reference\%20Manual.pdf ) (2016).

[13] Naip barajı mansap şartı tedbirleri yapım işi ışıklar deresi plan profil ve tip kesiti, hidrolik değerler tablosu, DSİ 11. Bölge Müdürlüğü, Edirne, (2015).

[14] DSİ, Dere yatakları için pürüzlülük katsayısı belirleme kılavuzu, Orman ve Su İşleri Bakanlığı, Devlet Su İşleri Genel Müdürlüğü, Ankara, (2016).

[15] Kutupluoğlu V., Akpınar A., Bingölbali B., Çakmak R.E. Marmara Denizi üzerinde maksimum belirgin dalga yüksekliklerinin alansal dağılımları. 9. Kıyı Mühendisliği Sempozyumu, 617-628, Adana, (2018). 